\title{
Influence of Soft Tissue Thickness on Peri-Implant Marginal Bone Loss: A Systematic Review and Meta-Analysis
}

Fernando Suárez-López del Amo, * Guo-Hao Lin, * Alberto Monje, * Pablo Galindo-Moreno, ${ }^{\dagger}$ and Hom-Lay Wang*

Background: Multiple variables have been shown to affect early marginal bone loss (MBL). Among them, the location of the microgap with respect to the alveolar bone crest, occlusion, and use of a polished collar have traditionally been investigated as major contributory factors for this early remodeling. Recently, soft tissue thickness has also been investigated as a possible factor influencing this phenomenon. Hence, this study aims to further evaluate the influence of soft tissue thickness on early MBL around dental implants.

Methods: Electronic and manual literature searches were performed by two independent reviewers in several databases, including Medline, EMBASE, and Cochrane Oral Health Group Trials Register, for articles up to May 2015 reporting soft tissue thickness at time of implant placement and MBL with $\geq 12$-month follow-up. In addition, random effects meta-analyses of selected studies were applied to analyze the weighted mean difference (WMD) of MBL between groups of thick and thin peri-implant soft tissue. Metaregression was conducted to investigate any potential influences of confounding factors, i.e., platform switching design, cement-/screw-retained restoration, and flapped/flapless surgical techniques.

Results: Eight articles were included in the systematic review, and five were included in the quantitative synthesis and meta-analyzed to examine the influence of tissue thickness on early MBL. Meta-analysis for the comparison of MBL among selected studies showed a WMD of $-0.80 \mathrm{~mm}(95 \%$ confidence interval -1.18 to $-0.42 \mathrm{~mm})(P<0.0001)$, favoring the thick tissue group. Metaregression of the selected studies failed to demonstrate an association among MBL and confounding factors.

Conclusion: The current study demonstrates that implants placed with an initially thicker peri-implant soft tissue have less radiographic MBL in the short term. J Periodontol 2016;87:690-699.

\section{KEY WORDS}

Alveolar bone loss; dental implant-abutment design; dental implants; endosseous dental implantation; evidence-based dentistry; review, systematic.

\footnotetext{
* Department of Periodontics and Oral Medicine, University of Michigan School of Dentistry, Ann Arbor, MI.

$\dagger$ Department of Oral Surgery and Implant Dentistry, University of Granada, Granada, Spain.
}

2 reservation of crestal marginal bone remains one of the most desired outcomes in implant dentistry. ${ }^{1}$ Traditionally, marginal bone loss (MBL) $<1.5 \mathrm{~mm}$ was defined as a reference point for successful implant treatment after 1 year of loading. ${ }^{2}$ However, with the use of new surface technologies and new implant designs and the availability of new research on factors affecting bone remodeling, ${ }^{3}$ this concept should be re-defined; having $1.5 \mathrm{~mm}$ of MBL is no longer acceptable during the first year in function. In fact, a recent investigation has demonstrated that $96 \%$ of implants with MBL $>2$ mm during the first 18 months presented with $\geq 0.44 \mathrm{~mm}$ bone loss 6 months postloading. ${ }^{4}$ This initial remodeling has traditionally been related to a variety of factors, including inadequate occlusion, ${ }^{5}$ the presence of a microgap, ${ }^{6}$ use of an implant with a smooth collar, ${ }^{7}$ infection, ${ }^{8}$ and more importantly, soft tissue thickness and its influence during re-establishment of the biologic width. ${ }^{9}$

Progressive MBL around the implant neck is a prelude to peri-implantitis development. ${ }^{4}$ Hence, minimizing or preventing this initial bone remodeling is of paramount importance, starting at the time of implant placement. With this purpose in mind, many researchers have tested the efficacy of different methods, such as platform switching (PS), ${ }^{10}$

doi: 10.1902/jop.2016.150571 
different apico-coronal positions of the implant with regard to the alveolar crest, ${ }^{11}$ and laser-modified implant surfaces. ${ }^{12}$

Avoiding bone loss resulting from the presence of a smooth implant neck can be as simple as positioning the machined area above the bone level. ${ }^{13}$ However, when aiming at distancing the microgap away from the alveolar bone, several methods have been investigated, namely, moving this implantabutment interface vertically and horizontally. ${ }^{10,11}$ Supracrestal positioning of $\approx 2 \mathrm{~mm}$ of the microgap can minimize its influence on bone remodeling. ${ }^{11}$ Horizontally, the concept of PS was introduced by Lazzara and Porter in 2006. ${ }^{10}$ It simply refers to moving the implant-abutment connection inward, so that the microgap is farther away horizontally from the alveolar bone. The rationale resides in this microgap acting as a reservoir for bacterial colonization, accumulating an inflammatory cell infiltrate that, because of its proximity to the bone, may trigger bone resorption. ${ }^{6,14-16}$ Hence, the farther away from the crestal bone, the less influence on its stability. ${ }^{10}$ Accordingly, the concept of PS has been widely studied during the last decade and shows promising results. ${ }^{17-19}$ Multiple randomized controlled trials as well as systematic reviews have confirmed its efficacy in maintaining crestal bone. ${ }^{17,20,21}$

Nonetheless, most studies aiming at minimizing early physiologic MBL by means of different techniques lack proper analysis regarding mucosal thickness at the time of implant placement. ${ }^{17-19}$ As early as 1996, mucosal thickness was proven to be a significant factor in marginal bone stability, when it was demonstrated that if a minimal requirement for biologic width (BW) formation is not satisfied, providing enough surface for both junctional epithelium and connective tissue attachments, bone resorption will occur. $^{9}$ Not surprisingly, a recent clinical trial investigated the influence of soft tissue thickness on initial bone remodeling after fixture installation, concluding that if a minimum $2 \mathrm{~mm}$ is not present during Stage 1 surgery, bone resorption will occur regardless of the use of laser-microtextured collars and PS connections. ${ }^{22}$

This systematic review evaluates the influence of soft tissue thickness at the time of implant placement on peri-implant MBL.

\section{MATERIALS AND METHODS}

\section{Information Sources}

Electronic and manual literature searches were performed by two independent reviewers (FSLA and $A M)$ in several databases, including Medline, EMBASE, and Cochrane Oral Health Group Trials Register, for articles up to May 2015 in the English language.

\section{Patient, Intervention, Comparison, Outcome (PICO) Question}

$\mathrm{P}=$ healthy patients receiving $\geq 1$ dental implants; $\mathrm{I}=$ direct measurements of soft tissue thickness at time of implant placement and radiographic MBL measured after implant placement with a minimum follow-up of 12-months; $\mathrm{C}=$ influence of thick and thin peri-implant soft tissue and other variables, if any, on MBL; O = weighted mean difference (WMD) of MBL between groups of thick and thin peri-implant soft tissue; $\mathrm{O}_{1}=\mathrm{MBL}$; and $\mathrm{O}_{2}=$ significance of other confounding factors for MBL (i.e., implant-abutment design, surgical technique [flap versus flapless], and type of restoration [screw versus cemented]).

\section{Screening Process}

Three major electronic databases were screened. For the PubMed library, combinations of controlled terms (MeSH and EMTREE) and keywords were used whenever possible. In addition, other terms not indexed as MeSH and filters were applied. As such, the key terms used were: ${ }^{(}\left(\left({ }_{(}(((\right.\right.$dental implant $[\mathrm{MeSH}$ Terms]) OR dental implantation[MeSH Terms]) OR dental implants[MeSH Terms]) OR dental implantation, osseo-integrated[MeSH Terms]) AND marginal bone loss[Title/Abstract]) OR crestal bone loss[Title/ Abstract]) AND tissue thickness[Title/Abstract]) OR tissue biotype[Title/Abstract]) OR tissue phenotype [Title/Abstract]) AND (Clinical Trial[ptyp] AND Humans[Mesh])). Because of the limited number of articles indexed following that strategy, a broader screening was conducted at the same database: (((((dental implants[Title/Abstract]) AND bone loss [Title/Abstract]) OR marginal bone loss[Title/ Abstract]) OR crestal bone loss[Title/Abstract]) AND soft tissue[Title/Abstract]) OR tissue thickness[Title/ Abstract] AND Humans[Mesh] AND (Clinical Trial [ptyp] AND Humans[Mesh])). For EMBASE and Cochrane, the key terms used were (Title, Abstract, Keywords): 'dental implant'/exp OR 'dental implant' AND ('bone loss'/exp OR 'bone loss') AND ('soft tissue'/exp OR 'soft tissue') AND ('thickness'/exp OR 'thickness') OR ('biotype'/exp OR 'biotype'). The screening in such databases was limited to 'clinical trials' AND 'humans.' In addition, an electronic screening of gray literature in the New York Academy of Medicine Gray Literature Report was conducted as recommended by A Measurement Tool to Assess Systematic Reviews (AMSTAR). ${ }^{23}$

A manual search of periodontics-/implantologyrelated journals, including Journal of Dental Research, Journal of Clinical Periodontology, Journal of Periodontology, and International Journal of Periodontics \& Restorative Dentistry, from January 2014 to May 2015 was also performed to ensure a thorough screening process. References of all articles 


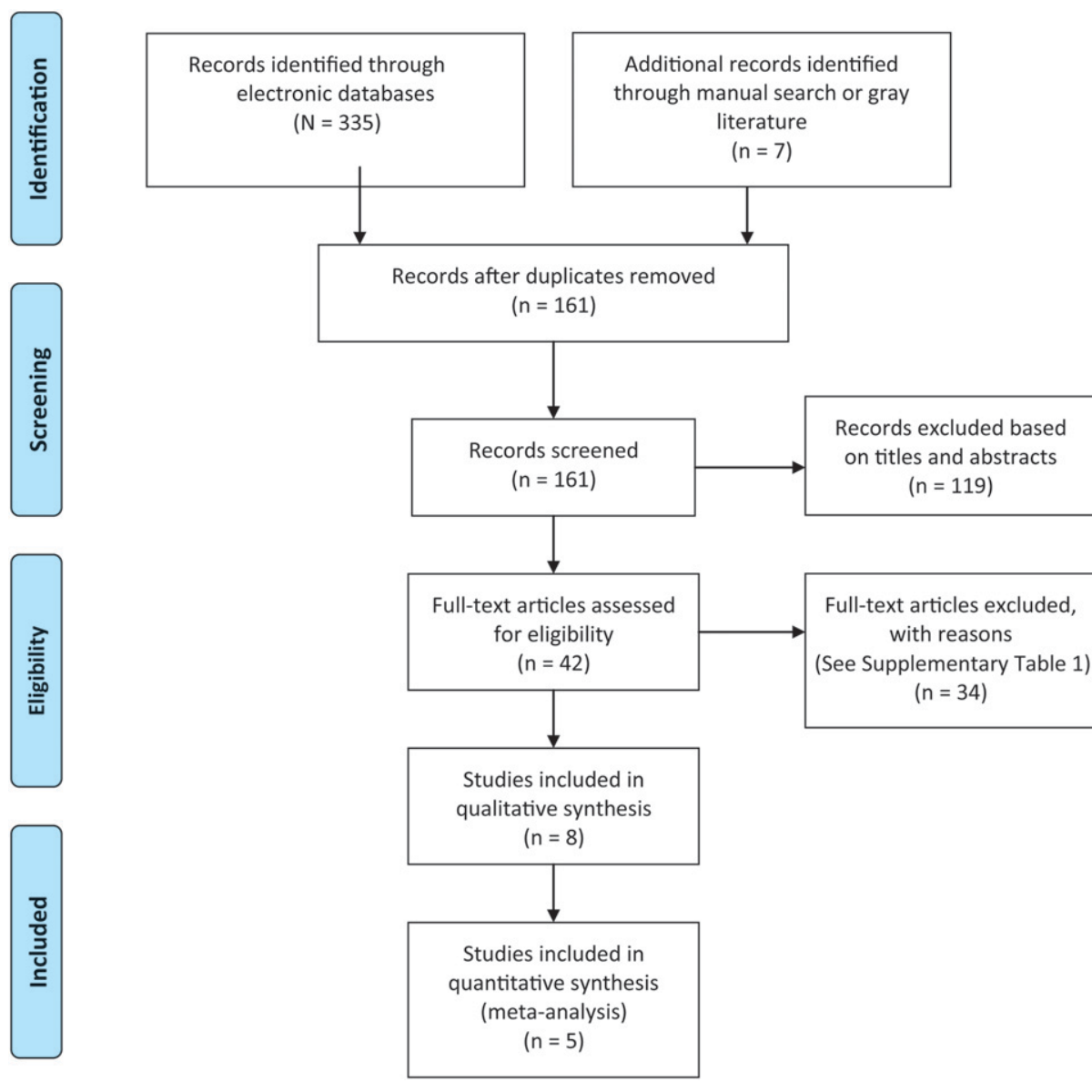

Figure I.

Preferred Reporting Items for Systematic Reviews and Meta-Analyses (PRISMA) flowchart of the screening process in the databases.

reporting $<12$-month results were also excluded. Immediate implants and implants with completely machined surfaces were not evaluated. Human trials with missing information were further excluded.

\section{Statistical Analyses}

Data were extracted by two observers (FSLA and AM) independently, from the papers that met inclusion criteria. If any disagreement was found, another reviewer was consulted (HLW). The difference of MBL around implants with thin and thick soft-tissue thickness at time of implant placement was the primary outcome. Pooled WMD of MBL was estimated using software. ${ }^{\ddagger}$ The contribution of each article was weighed. Random effects meta-analyses of the selected studies were applied to avoid bias caused by methodologic differences among studies. Forest plots were produced to graphically represent the difference in outcomes of thin and thick tissue groups for all included studies using implants as the analysis unit. A $P$ value of 0.05 was used as the level of significance. Heteroge-

reviewed in full text were further screened to check all available articles. Potential articles were examined in full-text by two reviewers (FSLA and AM) independently, and the articles' eligibility for this review was confirmed after discussion. The level of agreement between the reviewers regarding study inclusion was calculated using $\kappa$ statistics.

\section{Eligibility Criteria}

Articles were included in this systematic review if they met the following criteria: 1) human prospective and randomized controlled trials involving $\geq 10 \mathrm{im}$ plants with a minimum follow-up of 12 months; 2) only implants with rough surfaces were evaluated; 3 ) studies had to report the soft tissue thickness at time of implant placement, directly measured from the implant site at the crest; and 4) comparison between thin $(<2 \mathrm{~mm})$ and thick $(\geq 2 \mathrm{~mm})$ tissue groups in terms of MBL measured radiographically at 12 months had to be reported. Case reports and case series with $<10$ implants were excluded, and review articles, retrospectives, animal studies, and studies neity was assessed with $\chi^{2}$ test and $I^{2}$ test, with ranges from $0 \%$ to $100 \%$; lower values represent less heterogeneity. To avoid bias from combining differently designed studies, meta-analysis with the same level (crestal or supracrestal) of implant placement was performed in subgroups. In addition, funnel plots were used to assess the presence of publication bias. Regression analysis was performed to analyze the potential impact of confounding factors, including PS design, cement-/screw-retained restoration, and flap/flapless surgical techniques, on primary outcome. The reporting of these metaanalyses adheres to the Preferred Reporting Items for Systematic Review and Meta-Analyses statement (Fig. 1). ${ }^{24}$

\section{Quality Assessment}

The quality of all selected randomized controlled trials (RCTs) was assessed using the criteria modified from

\footnotetext{
$\ddagger$ Review Manager, v.5.0, The Nordic Cochrane Centre, Copenhagen Denmark.
} 


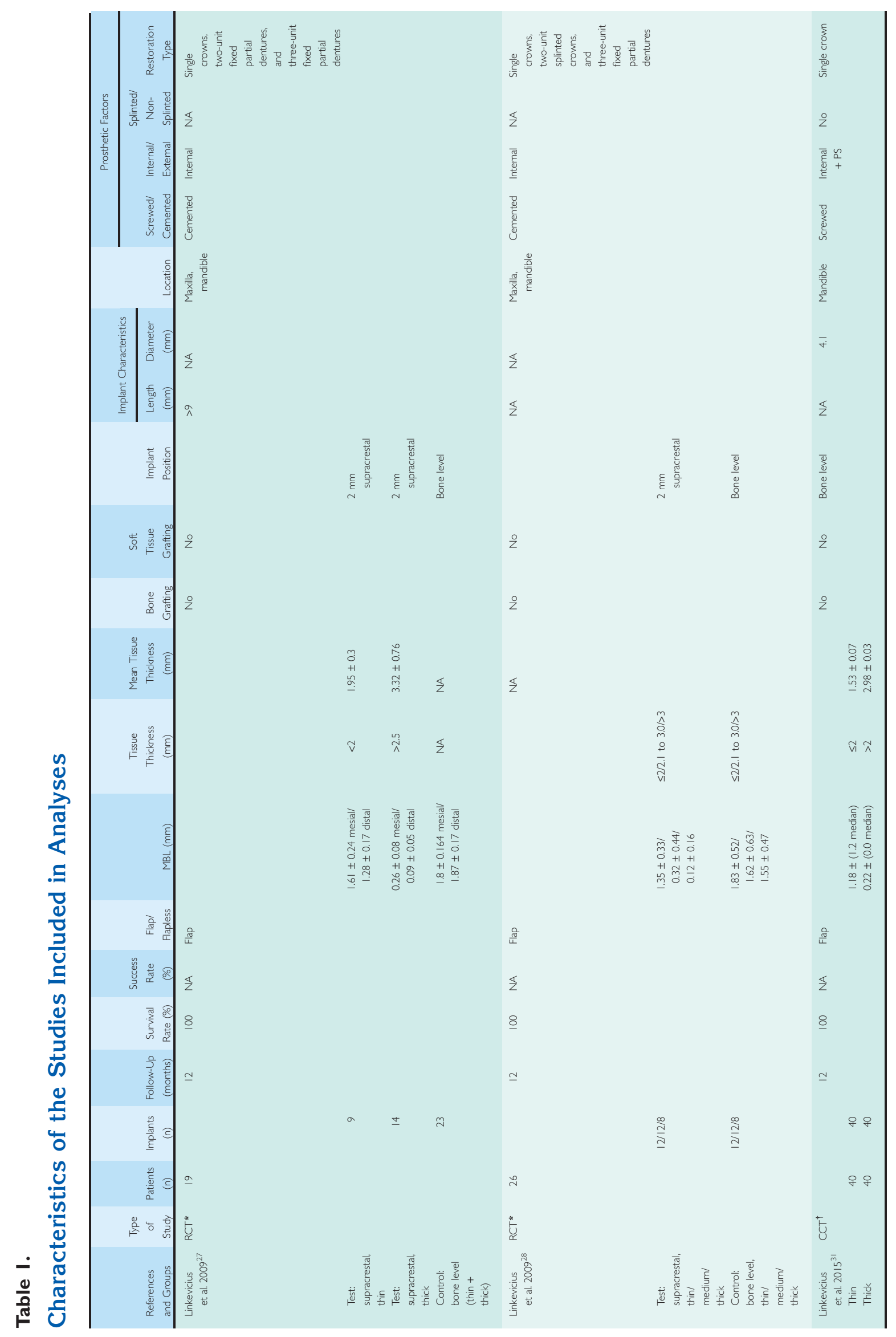




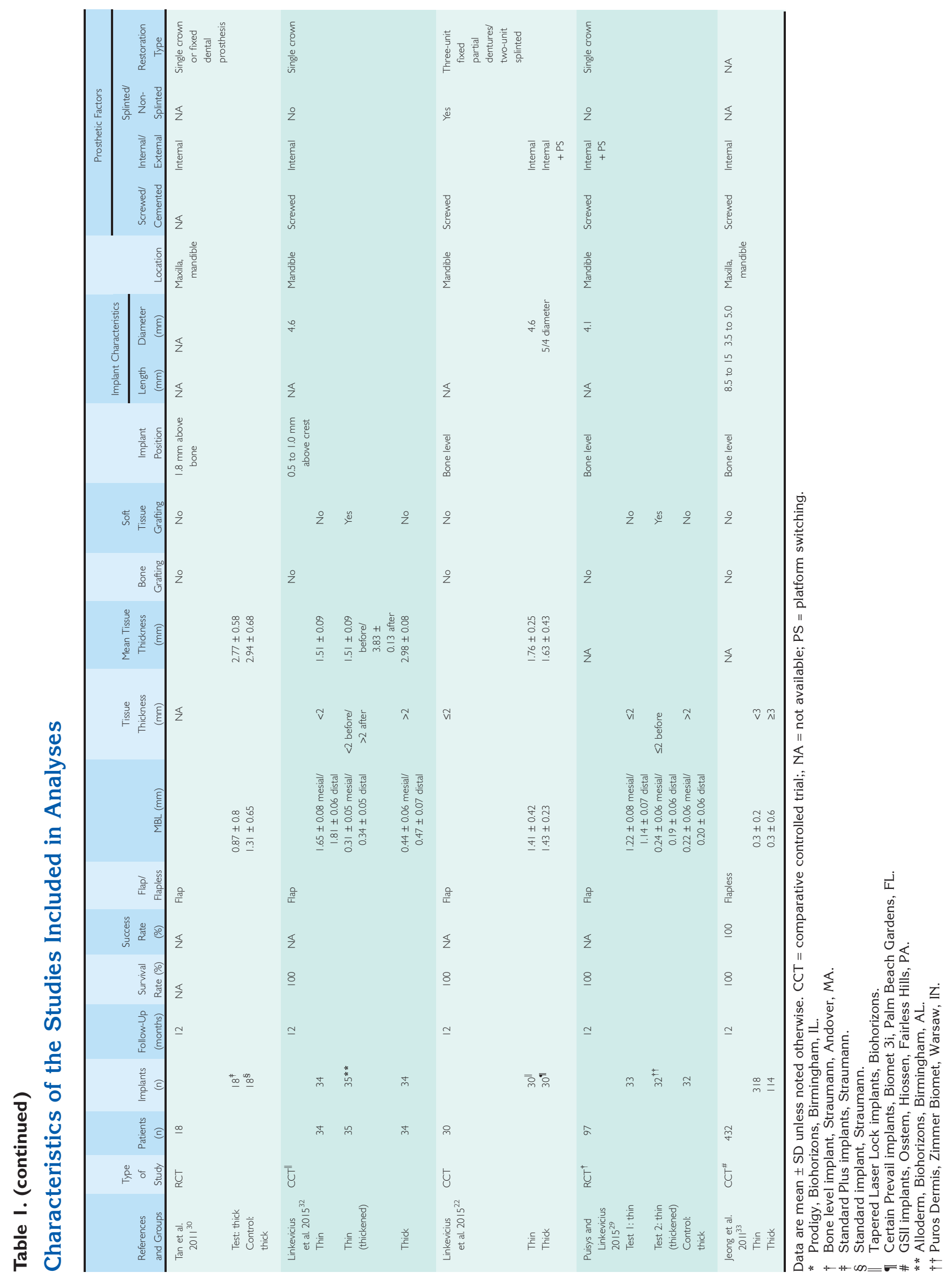




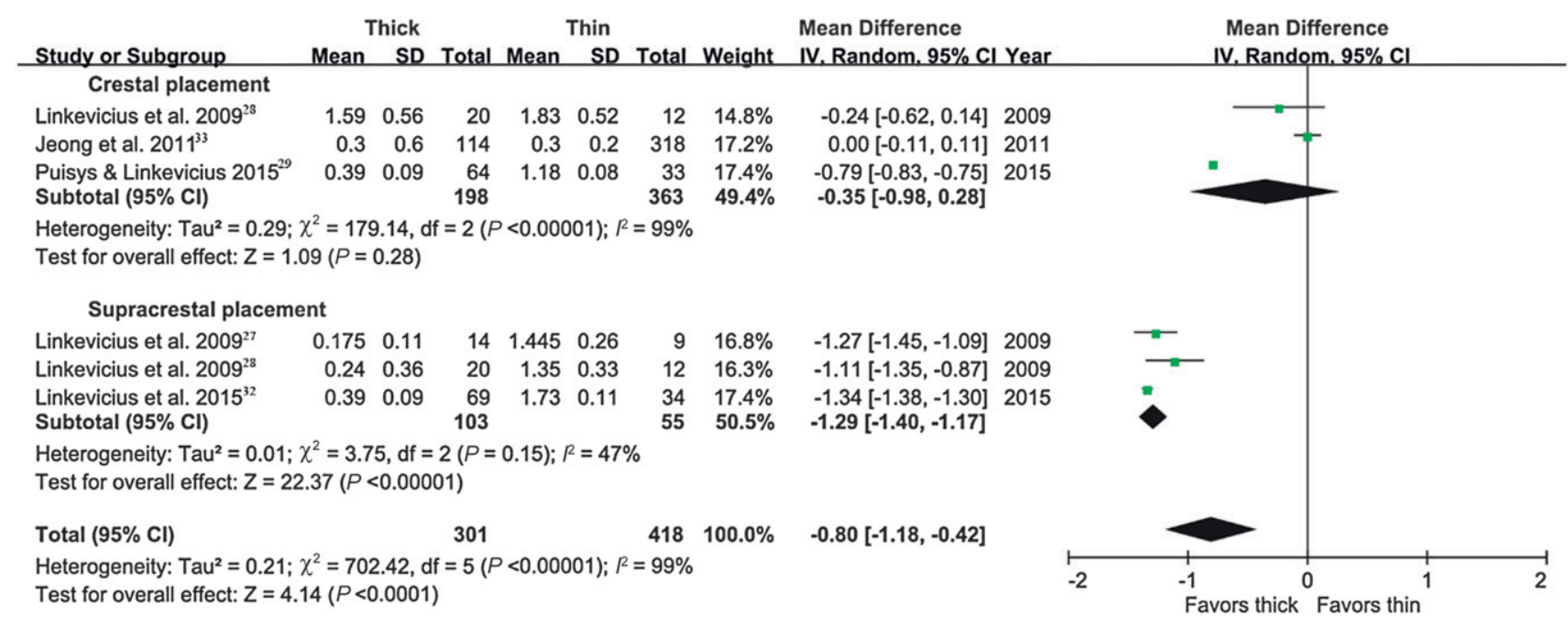

\section{Figure 2.}

Meta-analysis for the comparison of MBL among selected studies. For crestal placement, the WMD was $-0.35 \mathrm{~mm}(95 \% \mathrm{Cl}:-0.98$ to $0.28 \mathrm{~mm})(\mathrm{P}=$ 0.28). For supracrestal placement, the WMD was $-1.29 \mathrm{~mm}(95 \% \mathrm{Cl}:-1.40$ to $-1.17 \mathrm{~mm})(\mathrm{P}<0.000 \mathrm{l})$. For combined analysis, the WMD was

$-0.80 \mathrm{~mm}(95 \% \mathrm{Cl}:-1.18$ to $-0.42 \mathrm{~mm})(\mathrm{P}<0.000 \mathrm{I})$; this statistically significant difference favored the thick group.

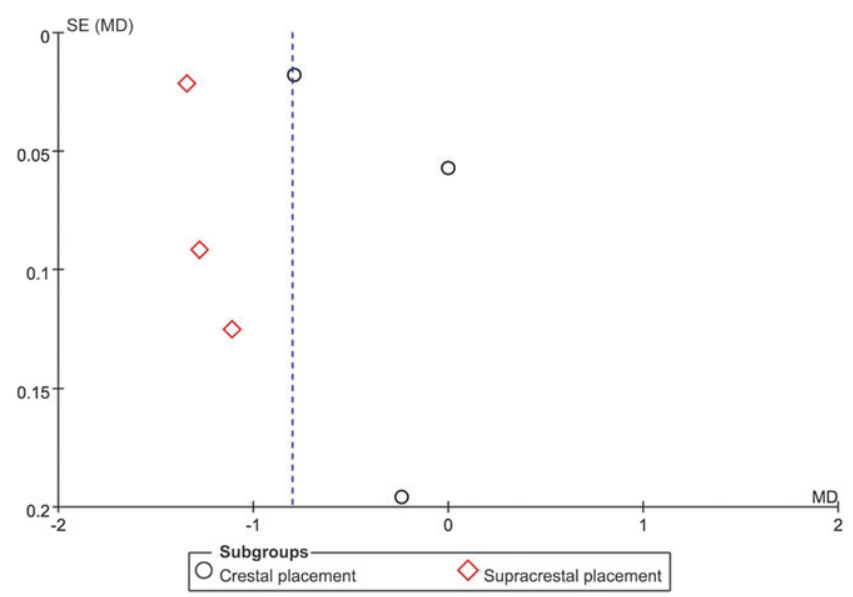

Figure 3.

Funnel plot of meta-analysis of $M B L$ among selected studies. $M D=$ mean difference.

the Cochrane Handbook for Systematic Reviews of Interventions. ${ }^{25}$ Parameters evaluated included: 1 ) appropriate population size; 2) definitions of inclusion and exclusion; 3 ) the presence of randomization; 4) methods of allocation concealment; 5) masking of examiners; 6) incomplete outcome data adequately addressed; and 7) free of suggestion of selective outcome reporting. The potential risk of bias was categorized as low if a study provided detailed information about all parameters above. Moderate risk was considered if a study failed to provide information on only one of the parameters, whereas if a study showed missing information of $>2$ parameters, the study was categorized as having a high risk of bias. All assessments were completed by a single examiner (GL). The NewcastleOttawa Scale was used to assess the quality of such studies for a proper understanding of nonrandomized studies. ${ }^{26}$

\section{RESULTS}

\section{Study Selection}

Initial screening yielded a total of 335 articles (116 PubMed, 187 EMBASE, and 32 Cochrane). Additionally, seven more articles were found through manual screening. Overall, 161 potentially relevant articles were selected after an evaluation of their titles and abstracts. Full texts of these articles were obtained and thoroughly evaluated. Of these, eight articles fulfilled the inclusion criteria and were included in the qualitative synthesis (Fig. 1; Table 1). A total of 34 articles were excluded. Articles along with reasons for exclusion and references are listed in supplementary Table 1 in online Journal of Periodontology. Of the eight articles included in the systematic review, five were also included in the quantitative synthesis and meta-analyzed to extract the influence of the variables on MBL. Details of all included studies are summarized in Table 1. The $\kappa$ value for inter-reviewer agreement for potentially relevant articles was 0.87 (titles and abstracts) and 0.89 (full-text articles), indicating a consistent agreement between the two reviewers.

\section{Characteristics of Included Articles}

Four articles are RCTs ${ }^{27-30}$ and four are comparative controlled trials. ${ }^{22,31-33}$ Of the eight articles included, three were further excluded from meta-analysis of MBL for the following reasons: 1) no comparison between thick and thin tissues (both groups presented 
Table 2.

\section{Risk of Bias Assessment of Included Studies}

\begin{tabular}{|c|c|c|c|c|}
\hline Criterion & $\begin{array}{l}\text { Linkevicius } \\
\text { et al. } 2009^{27}\end{array}$ & $\begin{array}{l}\text { Linkevicius } \\
\text { et al. } 2009^{28}\end{array}$ & $\begin{array}{c}\text { Puisys and } \\
\text { Linkevicius } 2015^{29}\end{array}$ & $\begin{array}{l}\text { Tan et al. } \\
2011^{30}\end{array}$ \\
\hline Study type & $\mathrm{RCT}$ & $\mathrm{RCT}$ & $\mathrm{RCT}$ & $\mathrm{RCT}$ \\
\hline Appropriate population size & Y & Y & Y & Y \\
\hline Definitions of inclusions and exclusions & Y & Y & Y & Y \\
\hline Presence of randomization & Y & Y & Y & Y \\
\hline Methods of allocation concealment & Y & Y & Y & Y \\
\hline Masking of examiners & NR & NR & NR & Y \\
\hline $\begin{array}{l}\text { Incomplete outcome data adequately } \\
\text { addressed }\end{array}$ & N & Y & Y & NR \\
\hline $\begin{array}{l}\text { Free of suggestion of selective outcome } \\
\text { reporting }\end{array}$ & Y & Y & Y & Y \\
\hline Estimated potential risk of bias & High & Moderate & Moderate & Moderate \\
\hline
\end{tabular}

NR $=$ not reported.

with thin mucosa); ${ }^{22}$ 2) no comparison between thick and thin tissues (both groups presented with thick mucosa); 30 and 3) no reporting of standard deviation for MBL. ${ }^{31}$

Of the five articles included in the meta-analysis, four used $2 \mathrm{~mm}$ as a cutoff point to divide between thin and thick tissue, ${ }^{27-29,32}$ and one study used $3 \mathrm{~mm} .{ }^{33}$ Two articles $^{29,32}$ divided tissue thickness into three different categories: thin, thin (thickened), and thick. Both of them used an allograft for increasing tissue thickness at time of implant placement. For the purpose of this review, both thickened groups were included and analyzed together with the thick group, since tissue thickness was $>2 \mathrm{~mm}$ after augmentation. All included articles used an internal connection system with or without the use of a smaller platform (PS).

\section{Meta-Analyses for MBL}

Five studies $27-29,32,33$ reported data on MBL of implants with thin and thick soft tissue. Of those five, two 29,33 reported that the implants were placed at crestal bone level; two 27,32 at supracrestal bone level; and one $e^{28}$ at both crestal and supracrestal bone levels. The statistical results from each of the selected studies were converted into effect sizes and combined in the meta-analysis. For crestal placement, WMD was $-0.35 \mathrm{~mm}$, with a $95 \%$ confidence interval $(\mathrm{CI})$ of -0.98 to $0.28 \mathrm{~mm}$ $(P=0.28)$. For supracrestal placement, the WMD was $-1.29 \mathrm{~mm}$ (95\% CI -1.40 to $-1.17 \mathrm{~mm})(P<0.0001)$. Interestingly, for combined analysis, the WMD was $-0.80 \mathrm{~mm}(95 \% \mathrm{Cl}-1.18$ to $-0.42 \mathrm{~mm})(P<0.0001)$, and this statistically significant difference favored the thick tissue group (Fig. 2). However, all comparisons presented considerable heterogeneity among studies. For the crestal and supracrestal placement subgroups and combined analyses, the $P$ values for $\chi^{2}$ test were $<0.0001,0.15$, and $<0.0001$, respectively, and $R$ values were $99 \%, 47 \%$, and $99 \%$, representing high, moderate, and high levels of heterogeneity among the included studies. A funnel plot of metaanalysis of MBL among selected studies is presented in Figure 3.

\section{Metaregression}

Three confounding factors: 1) the use of platform switching/matching designs; 2) cement-/screw-retained restoration types; and 3) flap/flapless surgical techniques were analyzed using metaregression. For MBL, the confounding factors did not significantly influence the outcome in any subgroup or combined analysis. The $P$ value of the metaregression for the use of different platform designs was 0.74 , for cement-/ screw-retained restoration types was 0.25 , and for flapped/flapless surgical techniques was 0.35 .

\section{Quality Assessment}

The results of risk of bias assessment for included RCTs are summarized in Table 2. Three studies ${ }^{28-30}$ were considered to have a moderate risk of bias, and one study ${ }^{27}$ was considered to have a high risk of bias. Four studies 22,31-33 were non-RCT, and hence, were evaluated according to the Newcastle-Ottawa Scale. The score obtained was $6.25 \pm 0.75$, showing an acceptable (low-medium risk of bias) methodologic level of evidence. 


\section{DISCUSSION}

As early as 1996, Berglundh and Lindhe demonstrated in an animal study that a certain amount of mucosal thickness is necessary to establish the socalled BW around dental implants. ${ }^{9}$ If deficient, crestal bone resorption will occur until enough space is established for both connective tissue and junctional epithelium. ${ }^{9}$ Although similar in composition and structure, it has been shown that this attachment apparatus is longer around dental implants compared with natural dentition, ${ }^{34-36}$ resulting in the requirement of more soft tissue height around implant fixtures. Results from the current meta-analysis confirmed previous observations demonstrating that $\geq 2 \mathrm{~mm}$ of soft tissue thickness is required for the establishment of the BW, and that in the presence of thin tissue $(<2 \mathrm{~mm})$, higher values of MBL will occur.

Multiple studies have previously supported the hypothesis that implants with thin crestal mucosa experience higher MBL. ${ }^{27,29,31}$ In addition to articles included in this meta-analysis, it is worth mentioning that investigations with different methodologies have also supported the importance of having a thick mucosa to preserve the crestal marginal bone. GalindoMoreno et al. ${ }^{37}$ and Vervaeke et al. ${ }^{38}$ concluded that implants with longer abutments had less MBL. Although both studies lacked measurements of tissue thickness at the time of implant placement, it could be hypothesized that longer abutments correspond with thicker tissues and, hence, less MBL is expected. ${ }^{37,38}$ In fact, $\geq 2 \mathrm{~mm}$ prosthetic abutment height is the cutoff point for preservation of bone around internal conical connection implants, data in accordance with the minimal amount of soft tissue required for establishment of BW and bone preservation suggested in this meta-analysis.

The influence of PS abutment designs on MBL has been widely investigated; however, the results are controversial, ${ }^{20,39,40}$ and no clear conclusion could be drawn at this point. Although clinical studies and systematic reviews have reported potential beneficial effects, ${ }^{17,20,39}$ multiple studies failed to demonstrate any significant difference if thin mucosa $(<2 \mathrm{~mm})$ is present. ${ }^{22,41}$ Accordingly, Vandeweghe and DeBruyn concluded that PS is effective only when mucosal thickness is enough for establishment of BW. ${ }^{42}$ In their RCT, marginal bone preservation was significantly different between PS and platform-matching connections only when mucosa was $>4.22 \mathrm{~mm}$. In this sense, Galindo-Moreno et al. recently reported that vertical mismatching, in relation with prosthetic abutment height, conditioned clinically by the keratinized mucosa width, is better than PS in the preservation of MBL. ${ }^{43}$ Furthermore, results from a recent investigation of implants restored with PS have concluded that bone resorption is mainly related to BW re-establishment rather than implant-abutment horizontal mismatching. ${ }^{18}$ These studies shed light on the potential correlation of peri-implant soft tissue thickness and MBL. ${ }^{18,42,43}$ Interestingly, the influence of peri-implant tissue thickness on MBL had never been systematically reviewed previously. The results of the current review confirm the beneficial effect on reducing MBL with the presence of thicker tissue, and this benefit outcome is more obvious when implants are placed supracrestally, with the use of either PS or platform-matched abutment connections.

To minimize early MBL as a consequence of lack of mucosal thickness for re-establishment of attachment apparatus at the time of implant placement, several studies performed soft tissue grafting by means of autogenous or allogeneic grafting materials to gain tissue thickness. ${ }^{29,32,44}$ In 2010, Wiesner et al. performed connective tissue grafting at the time of implant placement in 10 partially edentulous patients. ${ }^{44}$ Results at 12 months demonstrated better pink esthetic score and similar MBL for the grafted group $(0.8 \mathrm{~mm})$ versus non-grafted $(0.6 \mathrm{~mm})$, although differences were not significant. The reason that significant differences were not obtained might be a variety of different factors, including lack of baseline measurement for tissue thickness, differences in graft size, and the protocol for determining tissue thickness, which was measured at $10 \mathrm{~mm}$ below the alveolar crest. On the other hand, Linkevicius et al. ${ }^{28}$ and Puisys and Linkevicius ${ }^{29}$ demonstrated statistically significantly less MBL when thick tissue or augmented thin tissues were present compared with non-augmented thin tissues. Results from these studies showed that tissues with $>2 \mathrm{~mm}$ thickness, as measured perpendicularly from the crest at the time of implant placement, ${ }^{29,32}$ had less MBL.

In the subgroup analysis, the current review demonstrates that peri-implant tissue thickness plays a more important role in minimizing MBL when implants are placed supracrestally rather than at the level of the crest. The reason for this interesting outcome might be the different location of the implantabutment interface (microgap) between implant body and platform. Dibart et al. reported that an implant placed at the crestal bone level approximated the microgap to the bone, and thus MBL would occur due to possible bacterial leakage. ${ }^{45}$ This abutmentrelated inflammatory response could not be minimized even with a thicker peri-implant tissue; therefore, the MBL was significantly higher in crestal implant placement than supracrestal implant placement. Piattelli et al. suggested, in an animal model, that a more apical position of the implant-abutment connection implied a higher MBL than a more coronal position due to closer proximity to the bone of the inflammation zone associated with the implant-abutment 
interface. ${ }^{11}$ Consequently, supracrestal bone placement lengthens the distance between microgap and crestal bone, which might contribute to less MBL reported in the subgroup analysis of the current review.

The following limitations of the current review are noted. 1) The number of included papers for analyses were low $(n=5) .2)$ There are certain degrees of heterogeneity. Heterogeneity is related to the presence of confounding factors within and among the selected studies, for example, different study designs, follow-up periods, and patient demographic data. None of the included studies adjusted for the related confounding factors. 3) Multiple factors might affect the changes of MBL, such as smoking status, diabetes, and history of periodontal disease. However, all the selected articles excluded patients with these conditions; therefore, the meta-analysis of the current study may not be generalizable. Additionally, most included studies introduced screw-retained restorations, which also eliminated the influence of cement on MBL as possible etiology. 22,29,31-33 4) Most selected studies fulfilling the inclusion criteria were from the same study group, 22,27-29,31,32 which might increase the potential bias of the study outcome. 5) Only one author performed the assessment of the quality of the selected studies. 6) The current review includes only studies written in English, which potentially introduces selection bias. 7) Although initial circumferential bone loss around the neck of the implants was assumed, ${ }^{46}$ MBL was assessed only at the mesial and distal aspects of implants, missing information about the effect on the midfacial MB level. Future prospective studies should include this aspect in the study design.

\section{CONCLUSIONS}

The current study demonstrates that implants placed with an initially thicker peri-implant soft tissue have less radiographic MBL in the short term. Hence, soft tissue thickness evaluation at the time of implant placement is strongly encouraged for clinicians and researchers. In addition, with the presence of thin tissue, the use of soft tissue grafting seems to minimize the extent of peri-implant MBL.

\section{ACKNOWLEDGMENTS}

The authors do not have any financial interests, either directly or indirectly, in the products or information listed in the paper. This paper was partially supported by the University of Michigan Periodontal Graduate Student Research Fund. The authors report no conflicts of interest related to this study.

\section{REFERENCES}

1. Albrektsson T, Buser D, Sennerby L. Crestal bone loss and oral implants. Clin Implant Dent Relat Res 2012; 14:783-791.
2. Albrektsson T, Zarb G, Worthington P, Eriksson AR. The long-term efficacy of currently used dental implants: A review and proposed criteria of success. Int $J$ Oral Maxillofac Implants 1986;1:11-25.

3. Albrektsson T, Dahlin C, Jemt T, Sennerby L, Turri A, Wennerberg A. Is marginal bone loss around oral implants the result of a provoked foreign body reaction? Clin Implant Dent Relat Res 2014;16:155-165.

4. Galindo-Moreno P, León-Cano A, Ortega-Oller I, Monje A, O'Valle F, Catena A. Marginal bone loss as success criterion in implant dentistry: Beyond $2 \mathrm{~mm}$. Clin Oral Implants Res 2015;26:e28-e34.

5. Misch CE, Dietsh-Misch F, Hoar J, Beck G, Hazen R, Misch CM. A bone quality-based implant system: First year of prosthetic loading. J Oral Implantol 1999;25: 185-197.

6. Hermann JS, Schoolfield JD, Schenk RK, Buser D, Cochran DL. Influence of the size of the microgap on crestal bone changes around titanium implants. A histometric evaluation of unloaded non-submerged implants in the canine mandible. J Periodontol 2001; 72:1372-1383.

7. Wiskott HW, Belser UC. Lack of integration of smooth titanium surfaces: A working hypothesis based on strains generated in the surrounding bone. Clin Oral Implants Res 1999;10:429-444.

8. Barboza EP, Caúla AL, Carvalho WR. Crestal bone loss around submerged and exposed unloaded dental implants: A radiographic and microbiological descriptive study. Implant Dent 2002;11:162-169.

9. Berglundh T, Lindhe J. Dimension of the periimplant mucosa. Biological width revisited. J Clin Periodontol 1996;23:971-973.

10. Lazzara RJ, Porter SS. Platform switching: A new concept in implant dentistry for controlling postrestorative crestal bone levels. Int J Periodontics Restorative Dent 2006;26:9-17.

11. Piattelli A, Vrespa G, Petrone G, Iezzi G, Annibali S, Scarano A. Role of the microgap between implant and abutment: A retrospective histologic evaluation in monkeys. J Periodontol 2003;74:346-352.

12. Nevins M, Nevins ML, Camelo M, Boyesen JL, Kim DM. Human histologic evidence of a connective tissue attachment to a dental implant. Int $J$ Periodontics Restorative Dent 2008;28:111-121.

13. Hämmerle $\mathrm{CH}$, Brägger $U$, Bürgin $W$, Lang NP. The effect of subcrestal placement of the polished surface of ITI implants on marginal soft and hard tissues. Clin Oral Implants Res 1996;7:111-119.

14. Ericsson I, Persson LG, Berglundh T, Marinello CP, Lindhe J, Klinge B. Different types of inflammatory reactions in peri-implant soft tissues. J Clin Periodontol 1995;22:255-261.

15. Hermann JS, Buser D, Schenk RK, Cochran DL. Crestal bone changes around titanium implants. A histometric evaluation of unloaded non-submerged and submerged implants in the canine mandible. J Periodontol 2000;71:1412-1424.

16. Broggini N, McManus LM, Hermann JS, et al. Periimplant inflammation defined by the implant-abutment interface. J Dent Res 2006;85:473-478.

17. Canullo L, Fedele GR, Iannello G, Jepsen S. Platform switching and marginal bone-level alterations: The results of a randomized-controlled trial. Clin Oral Implants Res 2010;21:115-121.

18. Canullo L, Iannello G, Peñarocha M, Garcia B. Impact of implant diameter on bone level changes around 
platform switched implants: Preliminary results of 18 months follow-up a prospective randomized matchpaired controlled trial. Clin Oral Implants Res 2012;23: 1142-1146.

19. Canullo L, Iannello G, Götz W. The influence of individual bone patterns on peri-implant bone loss: Preliminary report from a 3-year randomized clinical and histologic trial in patients treated with implants restored with matching-diameter abutments or the platformswitching concept. Int J Oral Maxillofac Implants 2011; 26:618-630.

20. Strietzel FP, Neumann K, Hertel M. Impact of platform switching on marginal peri-implant bone-level changes. A systematic review and meta-analysis. Clin Oral Implants Res 2015;26:342-358.

21. Atieh MA, Ibrahim HM, Atieh AH. Platform switching for marginal bone preservation around dental implants: A systematic review and meta-analysis. $J$ Periodontol 2010;81:1350-1366.

22. Linkevicius T, Puisys A, Svediene O, Linkevicius R, Linkeviciene L. Radiological comparison of lasermicrotextured and platform-switched implants in thin mucosal biotype. Clin Oral Implants Res 2015;26: 599-605.

23. Shea BJ, Hamel C, Wells GA, et al. AMSTAR is a reliable and valid measurement tool to assess the methodological quality of systematic reviews. J Clin Epidemiol 2009;62:1013-1020.

24. Liberati A, Altman DG, Tetzlaff J, et al. The PRISMA statement for reporting systematic reviews and metaanalyses of studies that evaluate health care interventions: Explanation and elaboration. Ann Intern Med 2009;151:W65-W94.

25. Higgins JP, Green S. Cochrane Handbook for Systematic Reviews of Interventions, Version 5.1.0 (updated March 2011). The Cochrane Collaboration 2011. Available at: http:/www.cochranehandbook.org. Accessed November 19, 2015

26. Stang A. Critical evaluation of the Newcastle-Ottawa scale for the assessment of the quality of nonrandomized studies in meta-analyses. Eur J Epidemiol 2010; 25:603-605.

27. Linkevicius T, Apse P, Grybauskas S, Puisys A. The influence of soft tissue thickness on crestal bone changes around implants: A 1 -year prospective controlled clinical trial. Int J Oral Maxillofac Implants 2009; 24:712-719.

28. Linkevicius T, Apse P, Grybauskas S, Puisys A. Reaction of crestal bone around implants depending on mucosal tissue thickness. A 1 -year prospective clinical study. Stomatologija 2009;11:83-91.

29. Puisys A, Linkevicius T. The influence of mucosal tissue thickening on crestal bone stability around bone-level implants. A prospective controlled clinical trial. Clin Oral Implants Res 2015;26:123-129.

30. Tan WC, Lang NP, Schmidlin K, Zwahlen M, Pjetursson $B E$. The effect of different implant neck configurations on soft and hard tissue healing: A randomizedcontrolled clinical trial. Clin Oral Implants Res 2011; 22:14-19.

31. Linkevicius T, Puisys A, Steigmann M, Vindasiute E, Linkeviciene L. Influence of vertical soft tissue thickness on crestal bone changes around implants with platform switching: A comparative clinical study. Clin Implant Dent Relat Res 2015;17:1228-1236.

32. Linkevicius T, Puisys A, Linkeviciene L, Peciuliene V, Schlee $M$. Crestal bone stability around implants with horizontally matching connection after soft tissue thickening: A prospective clinical trial. Clin Implant Dent Relat Res 2015;17:497-508.

33. Jeong SM, Choi BH, Kim J, et al. A 1-year prospective clinical study of soft tissue conditions and marginal bone changes around dental implants after flapless implant surgery. Oral Surg Oral Med Oral Pathol Oral Radiol Endod 2011;111:41-46.

34. Abrahamsson I, Berglundh T, Wennström J, Lindhe J. The peri-implant hard and soft tissues at different implant systems. A comparative study in the dog. Clin Oral Implants Res 1996;7:212-219.

35. Abrahamsson I, Berglundh T, Moon IS, Lindhe J. Periimplant tissues at submerged and non-submerged titanium implants. J Clin Periodontol 1999;26:600-607.

36. Berglundh T, Lindhe J, Ericsson I, Marinello CP, Liljenberg $B$, Thomsen P. The soft tissue barrier at implants and teeth. Clin Oral Implants Res 1991;2:81-90.

37. Galindo-Moreno P, León-Cano A, Ortega-Oller I, et al. Prosthetic abutment height is a key factor in periimplant marginal bone loss. J Dent Res 2014;93(Suppl. 7):80S-85S

38. Vervaeke S, Dierens M, Besseler J, De Bruyn H. The influence of initial soft tissue thickness on peri-implant bone remodeling. Clin Implant Dent Relat Res 2014;16: 238-247.

39. Annibali S, Bignozzi I, Cristalli MP, Graziani F, La Monaca G, Polimeni A. Peri-implant marginal bone level: A systematic review and meta-analysis of studies comparing platform switching versus conventionally restored implants. J Clin Periodontol 2012;39:1097-1113.

40. Romanos GE, Javed F. Platform switching minimises crestal bone loss around dental implants: Truth or myth? J Oral Rehabil 2014;41:700-708.

41. Linkevicius T, Apse P, Grybauskas S, Puisys A. Influence of thin mucosal tissues on crestal bone stability around implants with platform switching: A 1-year pilot study. J Oral Maxillofac Surg 2010;68:2272-2277.

42. Vandeweghe S, De Bruyn H. A within-implant comparison to evaluate the concept of platform switching: A randomised controlled trial. Eur J Oral Implantology 2012;5:253-262.

43. Galindo-Moreno P, Leon-Cano A, Monje A, Ortega-Oller I, $\mathrm{O}$ Valle $\mathrm{F}$, Catena A. Abutment height influences the effect of platform switching on peri-implant marginal bone loss. Clin Oral Implants Res 2016;27:167-173.

44. Wiesner G, Esposito M, Worthington H, Schlee M. Connective tissue grafts for thickening peri-implant tissues at implant placement. One-year results from an explanatory split-mouth randomised controlled clinical trial. Eur J Oral Implantology 2010;3:27-35.

45. Dibart S, Warbington M, Su MF, Skobe Z. In vitro evaluation of the implant-abutment bacterial seal: The locking taper system. Int J Oral Maxillofac Implants 2005;20:732-737.

46. Grunder U, Gracis S, Capelli M. Influence of the 3-D bone-to-implant relationship on esthetics. Int $J$ Periodontics Restorative Dent 2005;25:113-119.

Correspondence: Dr. Fernando Suárez López del Amo, Department of Periodontics and Oral Medicine, University of Michigan School of Dentistry, 1011 North University Ave., Ann Arbor, MI 48109-1078. Fax: 734/936-0374; e-mail: fsuarez@umich.edu.

Submitted September 20, 2015; accepted for publication January 5, 2016. 